\title{
A Simple Stability-Indicating HPLC Method for Simultaneous Analysis of Paracetamol and Caffeine and Its Application to Determinations in Fixed-Dose Combination Tablet Dosage Form
}

\author{
Nafiu Aminu ${ }^{1,2 *}$, Siok-Yee Chan ${ }^{1}$, Nasir Hayat Khan', Ahmed Bassam Farhan', \\ Muhammad Nura Umar ${ }^{1,2}$ and Seok-Ming Toh ${ }^{1}$ \\ ${ }^{1}$ Discipline of Pharmaceutical Technology, School of Pharmaceutical Sciences, Universiti Sains Malaysia, \\ 11800 USM, Penang, Malaysia \\ ${ }^{2}$ Department of Pharmaceutics and Pharmaceutical Microbiology, Faculty of Pharmaceutical Sciences, \\ Usmanu Danfodiyo University, P.M.B. 2346, Sokoto, Nigeria
}

Received: 17 July 2017; accepted: 20 December 2017

\begin{abstract}
A simple, economic, rapid, reliable, and stability-indicating high-performance liquid chromatography (HPLC) method has been developed and validated for the simultaneous determination of paracetamol (PCM) and caffeine (CF) in solid dosage form. The chromatographic separations were achieved with a Waters Symmetry ${ }^{\circledR} \mathrm{C} 18$ column $(5 \mu \mathrm{m}, 4.6 \times 150 \mathrm{~mm})$, using a mixture of methanol and water $(40: 60, \mathrm{v} / \mathrm{v})$ as a mobile phase, under isocratic elution mode with a flow rate of $0.8 \mathrm{~mL} / \mathrm{min}$, and ultraviolet (UV) detection was set at $264 \mathrm{~nm}$. The oven temperature for the column was set and maintained at $35^{\circ} \mathrm{C}$. The method was validated according to International Conference on Harmonization (ICH) guidelines, and it demonstrated excellent linearity, with a correlation coefficient of 1 and 0.9999 for PCM and CF, respectively, over the concentration ranges of $15-300 \mu \mathrm{g} / \mathrm{mL}(\mathrm{PCM})$ and $2.5-50 \mu \mathrm{g} / \mathrm{mL}(\mathrm{CF})$. The retention time $\left(t_{\mathrm{R}}\right)$ was found to be $2.6 \pm 0.001$ and $3.5 \pm 0.002$ min for PCM and CF, respectively. Extensive stress degradation studies were conducted by subjecting the analytes to various stress conditions of acidic and alkaline hydrolysis as well as oxidative, photolytic, and heat degradations. The method was found to efficiently separate the analytes' peaks from that of the degradation products, without any variation in their retention times. The relative standard deviation (RSD) values of all recoveries for PCM and CF were less than $1.3 \%$. The method was found to be suitable for routine analysis of $\mathrm{PCM}$ and $\mathrm{CF}$ in pharmaceutical dosage form.
\end{abstract}

Keywords: Stability-indicating HPLC, paracetamol, caffeine, simultaneous determination, fixed-dose combination tablets, stress degradation study

\section{Introduction}

Typically, drug combination therapy is a type of therapeutic intervention for the treatment of certain ailments whereby more than one drug is administered to the patient either as a single pill (fixed-dose combination) or as separate multiple pills [1]. Even though the practice of drug combination therapy is nothing new, there has been a significant increase in the number of researched and approved combination therapies during the last 10 years, with many doctors and other medical practitioners recommending it for various diseases and conditions [2,3]. This increase is due to the fact that fixed-dose combination therapy has the potential to improve treatment response, decrease adverse event incidences, and minimize the development of resistance to antibiotics [2].

The fixed-dose combination of paracetamol (PCM) and caffeine $(\mathrm{CF})$ is primarily employed in conditions such as a migraine headache [4], which is a chronic and common disorder characterized by the recurrence of moderate to severe headaches which mostly affect one side of the head [5], muscular pains, toothaches, and dysmenorrhea (pain that occurs during menstruation) [6].

PCM is a para-aminophenol derivative ( $N$-acetyl-para-aminophenol) (Figure 1a), which possesses analgesic and antipyretic properties and weak anti-inflammatory activity [7]. The mechanism of action of PCM has not been completely elucidated till now [8]. However, recent findings suggest that it has inhibitory effects on cyclooxygenase (COX) enzymes, i.e., COX-1 and

\footnotetext{
* Author for correspondence: nafiu.aminu@udusok.edu.ng, nabgus@yahoo.com
}<smiles>CC(=O)Nc1ccc(O)cc1</smiles>

Figure 1. Structures of paracetamol (a) and caffeine (b)

COX-2, with stronger selectivity to COX-2 [8], and this leads to the inhibition of prostaglandin synthesis in the central nervous system and eventually results in antipyretic and analgesic effects [9].

CF (1,3,7-trimethylxanthine) (Figure 1b) is a central nervous system stimulating agent belonging to the methylxanthine class of compounds. It is a widely consumed compound that is added to a variety of edible products and beverages [10]. CF exerts its action through activation of noradrenaline neurons or interferes with the local release of dopamine, thereby enhancing alertness and brain activity [11]. It is also known to reversibly antagonize the action of adenosine on its receptor which results in preventing the onset of drowsiness triggered by adenosine [11, 12]. $\mathrm{CF}$ is used in drug combination therapy such as fixed-dose combination with PCM as an effective analgesic adjuvant for

This is an open-access article distributed under the terms of the Creative Commons Attribution-NonCommercial 4.0 International License (https://creativecommons.org/licenses/by-nc/4.0/), which permits unrestricted use, distribution, and reproduction in any medium for non-commercial purposes, provided the original author and source are credited, a link to the CC License is provided, and changes - if any - are indicated. 
ailments like a migraine headache, dysmenorrhea, cancer pain, postpartum pain, sore throat, and dental post-surgery pain [13].

The combination of PCM and CF was found to be significantly more effective than PCM alone in the treatment of a headache induced by tension [14], and the mild analgesic effect of CF synergistically enhances the action of PCM [15]. Tablet is a prominent dosage form that is widely used for fixed-dose combination drug delivery of PCM and CF.

Analytical methods for simultaneous quantification of these compounds are essential considering their versatile nature and importance. Many authors have reported analytical methods on the estimation of PCM and CF either separately or in combination with other $\operatorname{drug}(\mathrm{s})$ in pharmaceutical dosage forms or biological fluids by spectrophotometry [16], liquid chromatography-mass spectrometry [17], high-performance liquid chromatography (HPLC) [18], capillary electrophoresis [19], voltammetry [20], and thin-layer chromatography (TLC) [21].

A stability-indicating HPLC method for simultaneous determination of multiple drug substances and its products is essential in order to find out the intrinsic stability of the drugs in the formulation, as well as to establish degradation pathways of the drugs and its products [22]. The available stability-indicating HPLC methods [23, 24] for the simultaneous determination of PCM and $\mathrm{CF}$ in combination with other drug substances have some drawbacks. Firstly, the analysis is rather time and solvent consuming, i.e., $15 \mathrm{~min}$ for a single run at a high flow rate $(1.3 \mathrm{~mL} / \mathrm{min})$. The effects of the conducted stress studies at 0 h, i.e., immediately after exposing samples to degrading agents, and the effect of photolysis and heat have not been reported in the stress studies [23]. Lastly, the relationship between the degradation factors and the analytes was also not reported [24]. The International Conference on Harmonization (ICH) requirement for stress testing of analytical methods is that the drug substance and its product should be validated and the effects of temperature, humidity (where relevant), photolysis, oxidation, and acidic and alkaline hydrolysis should be demonstrated [25].

To the best of our knowledge, there is no reported stability-indicating HPLC method yet, for simultaneous determination of PCM and CF in the tablet dosage form; thus, we aimed to develop and validate a fast, accurate, economical, specific, and reliable method for determination of these drugs and their degradation products in the tablet dosage form. There are numerous fixed-dose combination of PCM $(500 \mathrm{mg})$ and CF $(65 \mathrm{mg})$ in tablet dosage form, readily available in the market in many parts of the world, such as Panadol ${ }^{\circledR}$ Extra (GSK), Hedex (Orion) etc. Therefore, in this work, a new, rapid, economic, reliable, specific, and stability-indicating HPLC method was used for the simultaneous determination of PCM and CF in tablet dosage form.

\section{Experimental}

Chemicals and Reagents. Analytically pure samples of PCM and CF were from Euro Chemo-Pharma, Malaysia. HPLC grade methanol was purchased from Merck (Darmstadt, Germany). AR grade hydrogen peroxide $\left(\mathrm{H}_{2} \mathrm{O}_{2}\right)$ and hydrochloric acid $(\mathrm{HCl})$ were purchased from $\mathrm{QReC}^{\circledR}$ Asia (Selangor, Malaysia). Sodium hydroxide $(\mathrm{NaOH})$ pellets and citric acid anhydrous were from R\&M (Essex, England). Formic acid was purchased from ASAX Chemicals (Australia). Distilled water was produced in-house by Favorit ${ }^{\circledR}$ W4L water system (Genristo Ltd., England).

The mobile phase was filtered through nylon filters $(0.45 \mu \mathrm{m})$ with titan membrane disc (Sun Sri, USA) and sonicated with Power sonic 405 (Seoul, Korea) before use. All sample solutions were filtered through $0.45 \mu \mathrm{m}$ polytetrafluoroethylene (PTFE) syringe membrane filters (Acrodisc, Pall Corporation, USA) prior to their injection into the HPLC system.

Commercially available tablets from GlaxoSmithKline (UK), labeled to contain a fixed-dose combination of PCM (500 mg) and CF $(65 \mathrm{mg})$ per tablet was purchased from a local pharmacy in Penang, Malaysia.

Apparatus and HPLC Conditions. The HPLC system was a Shimadzu (Japan) equipped with a solvent delivery unit (LC-20AD), ultraviolet-visible (UV-vis) detector, degasser, autosampler, column oven, and communications bus module. Data acquisition and processing were carried out by LabSolutions software installed in a desktop computer system. Waters Symmetry ${ }^{\circledR}$ C18 column $(5 \mu \mathrm{m}, 4.6 \times 150 \mathrm{~mm})$ (Ireland) was used for the chromatographic fractionations. Oven temperature for the column was set and maintained at $35^{\circ} \mathrm{C}$. The HPLC mobile phase used was methanol and water $(40: 60, \mathrm{v} / \mathrm{v})$, at a flow rate of $0.8 \mathrm{~mL} / \mathrm{min}$ under isocratic elution mode while UV detection was set at $264 \mathrm{~nm}$. Injection volumes $(10 \mu \mathrm{L})$ of calibration standard and test solutions were analyzed without further dilution. For each injection, a run time of 10 min was allowed in order to ensure full detection of both drugs and their clearance from the system before the next injection.

Preparation of Standard Calibration Solutions and Standard Calibration Curves. To prepare a standard stock solution, $60 \mathrm{mg}$ of PCM or $10 \mathrm{mg}$ of CF was accurately weighed using a Sartorius microbalance (Goettingen, Germany) and separately transferred into $100 \mathrm{~mL}$ volumetric flasks and dissolved in $70 \mathrm{~mL}$ of mobile phase (also a diluting solvent for the proposed method). Each flask was intermittently agitated for $1 \mathrm{~h}$ and sonicated for $15 \mathrm{~min}$ to ensure complete dissolution of the drugs. The flasks were then made up to the volume with the diluting solvent to give a stock solution with PCM and CF concentrations of $600 \mu \mathrm{g} / \mathrm{mL}$ and $100 \mu \mathrm{g} / \mathrm{mL}$, respectively.

From this standard stock solution, different concentration levels were prepared using the diluting solvent to obtain working calibration standard solutions of PCM and CF in the ranges of 15-240 and 2.5-40 $\mu \mathrm{g} / \mathrm{mL}$, respectively. Each solution was injected in 6 replicates into the HPLC system. The peaks' areas were recorded and plotted against the corresponding concentrations to yield the standard calibration curves of PCM and CF. Least square linear regression with error estimation was used to determine the $y$-intercept, slope, and correlation coefficients of the calibration graphs.

Preparation of Test Stock and Working Test Sample Solutions. The individual and average weight of 20 tablets labeled to contain $500 \mathrm{mg}$ of PCM and $65 \mathrm{mg}$ of CF per tablet were determined and then pulverized to a fine powder. The powder equivalent of $500 \mathrm{mg}$ of PCM and $65 \mathrm{mg}$ of CF was weighed and dispersed into a $100 \mathrm{~mL}$ volumetric flask containing about $50 \mathrm{~mL}$ of the diluent. The solution was intermittently agitated for $1 \mathrm{~h}$, sonicated for $15 \mathrm{~min}$ in order to extract the drugs, and then diluted to the mark with diluent to obtain a test stock solution having a PCM and CF concentration of $5 \mathrm{mg} / \mathrm{mL}$ and $0.65 \mathrm{mg} / \mathrm{mL}$, respectively.

From this test stock solution, a working test solution was prepared by making appropriate dilutions to obtain a final concentration of $125 \mu \mathrm{g} / \mathrm{mL}$ and $16.25 \mu \mathrm{g} / \mathrm{mL}$ for $\mathrm{PCM}$ and $\mathrm{CF}$, respectively. This solution was filtered and directly injected into the HPLC system.

\section{Stress Degradation Study}

Preparation of Standard Stock and Reference Solutions for Stress Degradation Studies. The stress studies' standard stock solution was prepared by accurately weighing and dissolving $45 \mathrm{mg}$ of $\mathrm{PCM}$ and $7.5 \mathrm{mg}$ of $\mathrm{CF}$ in a $25 \mathrm{~mL}$ volumetric flask by using the diluting solvent to obtain a solution having a concentration of 1800 and $300 \mu \mathrm{g} / \mathrm{mL}$ of $\mathrm{PCM}$ and $\mathrm{CF}$, 
respectively. A reference solution for stress degradation studies was prepared by diluting $1 \mathrm{~mL}$ of the stress studies' standard stock solution to $10 \mathrm{~mL}$ with the diluting solvent, to give a final concentration of $180 \mu \mathrm{g} / \mathrm{mL}$ and $30 \mu \mathrm{g} / \mathrm{mL}$ of PCM and CF, respectively.

Preparation of Test Stock Solution for Stress Degradation Studies. From the prepared test stock solution as described earlier, appropriate dilution was made to obtain a stress studies' test stock solution having a final concentration of $2.5 \mathrm{mg} / \mathrm{mL}$ and $0.325 \mathrm{mg} / \mathrm{mL}$ for PCM and $\mathrm{CF}$, respectively.

Acidic and Alkaline Hydrolysis. A volume of $1 \mathrm{~mL}$ of PCM and CF standard stock solution for stress studies was added into four $10 \mathrm{~mL}$ volumetric flasks. Then, $1 \mathrm{~mL}$ of $2 \mathrm{M}$ $\mathrm{HCl}$ or $2 \mathrm{M} \mathrm{NaOH}$ was added into 2 flasks for acid or alkali hydrolysis, respectively. For $0 \mathrm{~h}$ samples, the solutions were neutralized with $2 \mathrm{M} \mathrm{NaOH}$ or $2 \mathrm{M} \mathrm{HCl}$ immediately and adjusted to the mark with diluting solvent. Finally, the solutions were filtered and injected into the HPLC system. For $24 \mathrm{~h}$ samples, the mixture of the stress studies' standard stock solution and $2 \mathrm{M} \mathrm{HCl}$ or $2 \mathrm{M} \mathrm{NaOH}$ in the remaining 2 flasks was left on the bench for $24 \mathrm{~h}$ at the laboratory's temperature and humidity conditions $\left(25^{\circ} \mathrm{C} / 51 \%\right.$ relative humidity $\left.(\mathrm{RH})\right)$. The solutions were then treated as described for $0 \mathrm{~h}$ samples.

The test sample solution for stress studies was also prepared according to the procedure above.

Oxidative Degradation. A volume of $1 \mathrm{~mL}$ of the PCM and CF standard stock solution or test stock solution for stress studies was added into two $10-\mathrm{mL}$ volumetric flasks (for $0 \mathrm{~h}$ and $24 \mathrm{~h}$ samples). Then, $1 \mathrm{~mL}$ of $30 \% \mathrm{H}_{2} \mathrm{O}_{2}$ solution was added into each of the flasks. For the $0 \mathrm{~h}$ sample, the mixture was immediately diluted up to the mark with diluting solvent, filtered, and then analyzed. The other flask was kept on the bench for $24 \mathrm{~h}$ at the laboratory's temperature and humidity conditions $\left(25{ }^{\circ} \mathrm{C} / 51 \% \mathrm{RH}\right)$ and then treated as described for the $0 \mathrm{~h}$ sample.

Photolytic Degradation. A volume of $1 \mathrm{~mL}$ of the PCM and CF standard stock or test stock solution for stress studies was added into two $10 \mathrm{~mL}$ volumetric flasks. For the $0 \mathrm{~h}$ sample, the solution was immediately adjusted to the mark with the diluting solvent, filtered, and then analyzed. The other flask was stored for $24 \mathrm{~h}$ in an ultraviolet chamber (Ultra-Lum, Inc., California, USA) at a wavelength of $365 \mathrm{~nm}$. The sample was then treated as described for the $0 \mathrm{~h}$ sample.

Heat Degradation. A volume of $1 \mathrm{~mL}$ of the PCM and CF standard stock or test stock solution for stress studies was added into two $10-\mathrm{mL}$ volumetric flasks. For the $0 \mathrm{~h}$ sample, the solution was immediately adjusted to the mark with diluting solvent, filtered, and then analyzed. The other flask was heated at $80{ }^{\circ} \mathrm{C}$ in a water bath for $2 \mathrm{~h}$ and then treated as described for the $0 \mathrm{~h}$ sample.

Method Validation. The proposed HPLC method was validated as per ICH guidelines [26], and it involved demonstration of validation characteristics such as system suitability, specificity, linearity, range, accuracy, precision, robustness, limit of detection (LOD), and limit of quantification (LOQ).

System Suitability. System suitability is conducted to ensure that the complete testing system meets the intended expectations under the experimental conditions of the tests. This was achieved by injecting 10 replicates of the standard sample solution in the HPLC system, and the system suitability parameters for the proposed method were determined. The desirable parameters, i.e., tailing factor $\leq 2$, United States Pharmacopeia (USP) number of theoretical plates $>2000$, USP resolution $>2$, injection precision, and repeatability relative standard deviation (RSD) $\leq 2 \%$ [27], were calculated and recorded.
Specificity. Specificity of an ideal analytical method is its ability to detect the analytes in the presence of other constituents such as products of degradation, impurities, and excipients that are expected to be present [28]. The specificity of the proposed method was determined by subjecting the standard and test sample solutions to forced degradation by acidic and alkaline hydrolysis, oxidative, photolytic, and thermal stress. The resulting solutions were analyzed to demonstrate the proposed method's ability to detect the analytes in the presence of products of degradation and impurities.

Linearity and Range. The linearity of the developed method was studied by preparing and analyzing seven different concentrations of calibration standard solutions, over a range of 15-300 and 2.5-50 $\mu \mathrm{g} / \mathrm{mL}$ for PCM and CF, respectively. The calibration curves were developed by plotting the chromatogram's peak areas against corresponding concentrations. The relevant plot parameters such as correlation coefficient, the residual sum of squares, slope of the regression line, and $y$-intercept were calculated. All standard and test samples were prepared at concentration levels that fall within the range that covered the expected analytes' content.

Accuracy. The accuracy of the method was demonstrated by the recovery of PCM and CF from the tablet dosage form sample (test sample solution) and also from three spiked placebo (diluting solvent) solutions which were prepared from stock standard solutions corresponding to $50 \%, 100 \%$, and $150 \%$ of the analytes concentration in the test sample solution. The amount of each drug was calculated from the earlier made calibration curves, and the percentage recovery and percentage relative error ( $\%$ RE) were determined and used as an indicator for accuracy.

Precision. The precision of the proposed method was demonstrated by evaluation of intra-day and inter-day precision. Intra-day repeatability was determined by repeated injections of six independent solutions of spiked placebo solutions within the same day, while the inter-day precision was carried out by injections of the spiked placebo solutions on six different days, with a fresh sample for each day. For both intra-day and inter-day precision determinations, the spiked placebo solutions of PCM and $\mathrm{CF}$ at three concentration levels $(62.5,125$, and $187.5 \mu \mathrm{g} / \mathrm{mL}$ of PCM and $8.125,16.25$, and $24.375 \mu \mathrm{g} / \mathrm{mL}$ of $\mathrm{CF}$ ) were determined in triplicate. The percentage recovery and \% RSD were determined as a measure of precision.

Robustness. The robustness of a liquid chromatographic method should be determined to assess the effect of minor deliberate variations of the method's optimized parameters [26]. The robustness of the proposed method was assessed using standard sample solutions (125 and $16.25 \mu \mathrm{g} / \mathrm{mL}$ for PCM and $\mathrm{CP}$, respectively) that were prepared from stock standard solutions, by changing the flow rate $( \pm 0.1 \mathrm{~mL} / \mathrm{min})$, ratio of the mobile phase composition ( $\pm 2 \%$ of methanol), and column temperature $\left( \pm 2{ }^{\circ} \mathrm{C}\right)$. The standard deviation of the peak's areas and $\%$ RSD of the retention times were calculated.

Limit of Detection and Limit of Quantification. The LODs and LOQs of PCM and CF for the proposed method were determined based on the signal-to-noise ratios of 3:1 (LOD) and 10:1 (LOQ), as described in our previous method [29].

\section{Results and Discussion}

Method Development and Optimization of Chromatographic Conditions. Two different C18 columns (Agilent ZORBAX SB, $5 \mu \mathrm{m}, 4.6 \times 250 \mathrm{~mm}$ and Waters Symmetry ${ }^{\circledR}, 5 \mu \mathrm{m}, 4.6 \times$ $150 \mathrm{~mm}$ ) were tested as stationary phases for better separation and determination of PCM and CF peaks. The Waters Symmetry ${ }^{\circledR} \mathrm{C} 18$ column $(5 \mu \mathrm{m}, 4.6 \times 150 \mathrm{~mm})$ exhibited better separation parameters within a shorter period and therefore was 
selected for this study. The various mobile phases investigated for better separation and peak resolution are as follows: acetonitrile-water, acetonitrile-formic acid (0.2 and $0.1 \%)$, acetonitrile-citrate buffer ( $\mathrm{pH} 3-7)$, methanol-water, methanolformic acid $(0.2$ and $0.1 \%)$, and methanol-citrate buffer (pH 3-7), all at different organic to aqueous solvent ratios in the ranges of $10-90 \%$ and $90-10 \%$, respectively. Preliminary trials using acetonitrile and water at different combination ratios did not lead to analyte separation (Figure 2). Similarly, when methanol to citrate buffer or formic acid combinations was tried, they did not furnish desirable peak parameters in a short time and thus were dropped. For methanol-water combinations, there was poor peak resolution when a higher percentage of methanol was used. However, after several trials, PCM and CF were optimally fractionated with a solvent combination of methanol-water at a ratio of 40:60 v/v, under isocratic condition. This optimal mobile phase solvent was used for the preparation of all sample solutions and dilutions. The effect of flow rate $(0.3-1.2 \mathrm{~mL} / \mathrm{min})$, UV detection wavelength
(220-280 nm), injection volume $(5-20 \mu \mathrm{L})$, and column temperature $\left(25-45{ }^{\circ} \mathrm{C}\right)$ was also studied and adjusted accordingly. The optimal flow rate was $0.8 \mathrm{~mL} / \mathrm{min}$ which maintained the HPLC pump pressure at $9.5( \pm 0.1) \mathrm{Mpa}$. The optimal UV wavelength was $264 \mathrm{~nm}$, while $35^{\circ} \mathrm{C}$ was found to be the optimal column temperature and $10 \mu \mathrm{L}$ was the selected injection volume. The determining parameters used for choosing the optimal HPLC conditions were the solvent's costeffectiveness; ease of preparation (mobile phase); time required for the analysis; reproducibility of retention times; separation of analyte peaks from excipients, impurities, or other agents; and peak's sharpness, resolution, and symmetry. Figure 3a depicts the HPLC chromatogram of standard sample solution under optimal conditions with retention times for PCM and $\mathrm{CF}$ at $2.6 \pm 0.001 \mathrm{~min}$ and $3.5 \pm 0.002 \mathrm{~min}$, respectively.

\section{Method Validation}

System Suitability Test. To ensure the system performance as well as the accuracy and precision of the HPLC data collected, system suitability tests were conducted by analyzing the standard



Figure 2. Chromatogram indicating the unsuccessful separation of PCM and CF when eluted with acetonitrile and water (60:40, v/v)

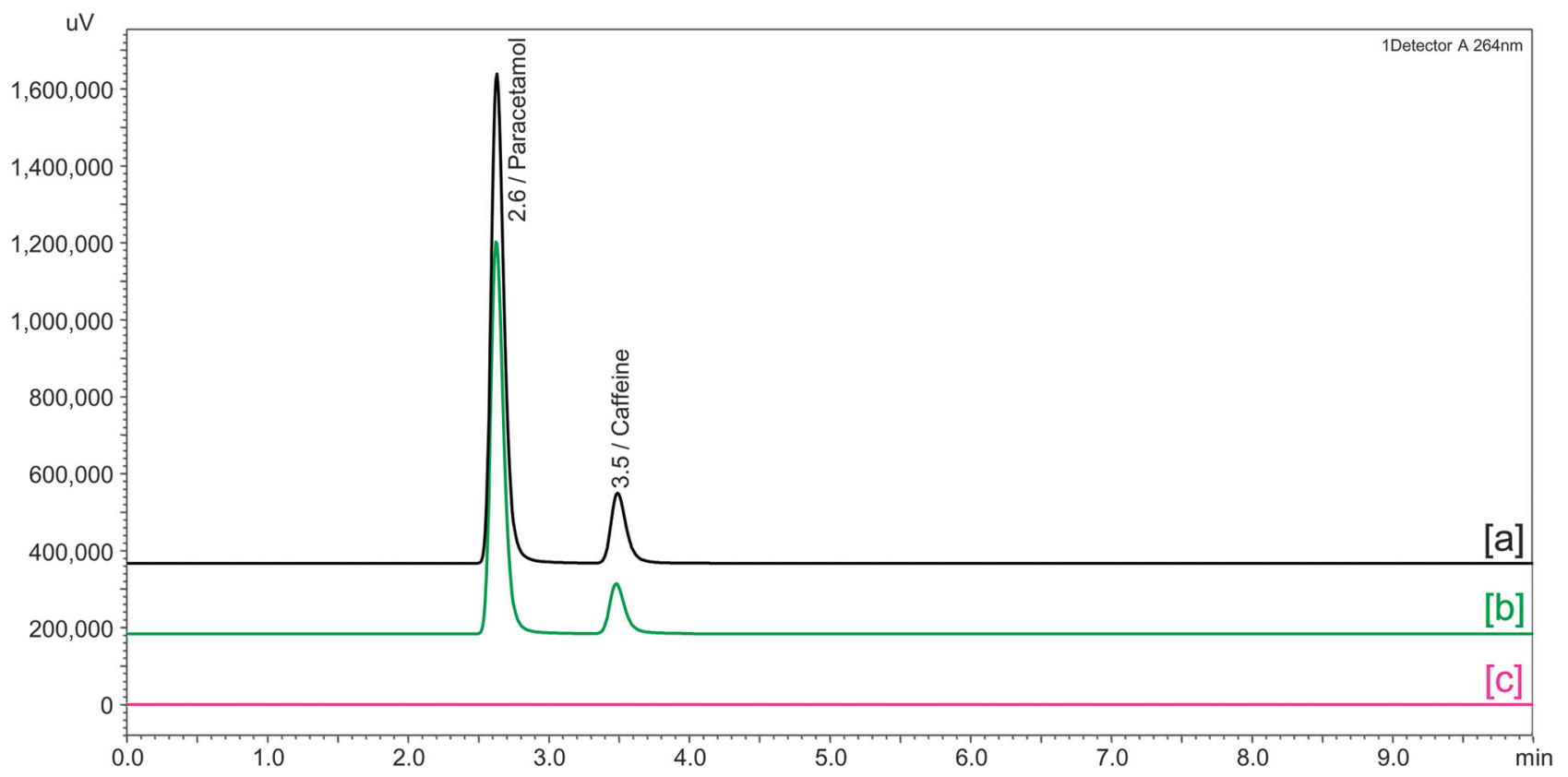

Figure 3. Chromatograms of the standard sample (a), tablet dosage form sample (b), and mobile phase (c) for the proposed method under optimized conditions, with retention times of $2.6 \pm 0.001 \mathrm{~min}$ and $3.5 \pm 0.002 \mathrm{~min}$ for PCM and CF, respectively 
solution of PCM $(125 \mu \mathrm{g} / \mathrm{mL})$ and CF $(16.25 \mu \mathrm{g} / \mathrm{mL})$ in 10 replicates, and the result is presented in Table 1 . The proposed method's parameters for both analytes were found to be within acceptable limits.

Robustness. Following small deliberate subjected variations in the method's mobile phase composition, flow rate, and column temperature, there were no significant differences found in the peak area and the retention times of the analytes. The standard sample solution with a concentration of $125 \mu \mathrm{g} / \mathrm{mL}$ of PCM and $16.25 \mu \mathrm{g} / \mathrm{mL}$ of CF was used for the study. As shown in Table 2 , the $\%$ RSD values were $<2 \%$ for both PCM and $\mathrm{CF}$, which indicated adequate robustness of the method.

Calibration Curve, Linearity, and Range. The standard calibration curves were obtained by plotting peak areas against corresponding concentrations for both $\mathrm{PCM}$ and $\mathrm{CF}$ in the ranges of $15-300$ and $2.5-50 \mu \mathrm{g} / \mathrm{mL}$, respectively. Both curves exhibited excellent linearity within the analyzed concentration ranges. The linear regression equation was $y=$ $27811.18 x+14735.54$ and $y=4720.1 x-8482.3$ for PCM and CF, respectively. The regression coefficient $(R)$ and correlation coefficient $\left(R^{2}\right)$ requirement for ICH that $R$ should be $\geq 0.999$, and $R^{2}$ should be $\geq 0.995[26,27]$ were fulfilled by both the analytes. Statistical data for the calibration curves for PCM and CF are detailed in Table 1.
Accuracy. Accuracy was calculated as \% recovery from the dosage form sample solution and placebo solutions that were spiked with a standard mixture of PCM and CF at three different concentration levels. The accuracy results presented in Table 1 indicated satisfactory recoveries for both drugs.

Precision. The precision of the proposed method was evaluated through intra-day repeatability and inter-day variation study. The intra-day repeatability for the determination of PCM and CF was conducted by analyzing the spiked placebo solutions six times within the same day, under the same analytical conditions. The inter-day precision was carried out as described under intraday repeatability but on six consecutive days, with three determinations on fresh sample each day. Precision was expressed as \% recovery and \% RSD for PCM and CF (Table 1). The precision requirement for intra-day and inter-day evaluations demands an RSD $\leq 2 \%$ [27]. All data showed good agreement among the individual results under test.

Specificity. The developed method demonstrated adequate specificity as there was no interference from the tablet dosage form constituents (i.e., excipients) or from other impurities in any of the drug retention time regions. Figure 3 depicts a comparison between chromatograms of the standard sample, tablet dosage form, and mobile phase (also dilution solvent) for the proposed method. When stress degradation studies were

Table 1. The proposed method validation results

\begin{tabular}{|c|c|c|c|}
\hline Parameter & Paracetamol & Caffeine & $\begin{array}{c}\text { Acceptable limits } \\
{[27,30]}\end{array}$ \\
\hline \multicolumn{4}{|l|}{ System suitability $(n=10)$} \\
\hline$t_{\mathrm{R}}( \pm \mathrm{SD})$ & $2.63(0.001)$ & $3.49(0.002)$ & - \\
\hline Number of theoretical plates $( \pm \mathrm{SD})$ & $4001.1(54.17)$ & $5020.3(72.58)$ & $>\overline{2} 000$ \\
\hline Resolution $( \pm \mathrm{SD})$ & - & $4.73(0.008)$ & $>2$ \\
\hline Injection repeatability $^{a}(\%$ RSD) & 0.04 & 0.06 & $\leq 1 \%$ \\
\hline \multicolumn{4}{|l|}{ Linear regression } \\
\hline Slope & $27,811.17589$ & $28,320.897$ & - \\
\hline$y$-Intercept & $14,734.54043$ & -8482.3221 & - \\
\hline$R^{2}$ & 1 & 0.9999 & $>0.999$ \\
\hline Ranges $(\mu \mathrm{g} / \mathrm{mL})$ & $15-300$ & $2.5-50$ & - \\
\hline \multicolumn{4}{|l|}{ Accuracy } \\
\hline Average recovery $(\%)$ & $96.55^{b}, 100.6^{c}$ & $103.55^{b}, 101.48^{c}$ & $100 \pm 2 \%$ \\
\hline Average RE $(\%)$ & $-3.45^{d}, 0.60^{e}$ & $3.55^{d}, 1.48^{e}$ & $\pm 2 \%$ \\
\hline Average RSD (\%) & $0.66^{f}, 0.39^{g}$ & $1.15^{f}, 0.90^{g}$ & - \\
\hline Average intra-day precision ${ }^{h}(\%$ RSD) & 0.62 & 1.02 & $\leq 2 \%$ \\
\hline Average inter-day precision ${ }^{i}(\%$ RSD) & 1.28 & 1.19 & $\leq 2 \%$ \\
\hline $\mathrm{LOD}(\mu \mathrm{g} / \mathrm{mL})$ & 0.01 & 0.01 & - \\
\hline LOQ $(\mu \mathrm{g} / \mathrm{mL})$ & 0.02 & 0.02 & - \\
\hline $\begin{array}{l}{ }^{a} \mathrm{RSD} \text { values for injection repeatabil } \\
{ }^{b} \text { Percentage recovery values of analy } \\
{ }^{c} \text { Percentage recovery values of analy } \\
{ }^{d} \text { Percentage relative error values of } \\
{ }^{e} \text { Percentage relative error values of } \\
{ }^{f} \mathrm{RSD} \text { values for recoveries of analyt } \\
{ }^{g} \mathrm{RSD} \text { values for recoveries of analy } \\
{ }^{h} \mathrm{RSD} \text { values for precision of six san } \\
{ }^{i} \mathrm{RSD} \text { values for precision of analyte }\end{array}$ & $\begin{array}{l}(n=10) \text {. } \\
\text { dosage form samples } \\
\text { d placebo samples at } t \\
\text { ablet dosage form sam } \\
\text { piked placebo samples } \\
\text { dosage form samples ( } \\
\text { placebo samples at th } \\
\text { tes analysis at three co } \\
\text { at three concentration }\end{array}$ & $\begin{array}{l}\text { levels }(n=6) \text {. } \\
\text { tion levels }(n=6) \text {. } \\
\text { levels }(n=6) \text {. } \\
\text { within the same day ( } \\
\text { secutive days }(n=3) \text {. }\end{array}$ & \\
\hline
\end{tabular}

Table 2. Results of the robustness evaluation for the proposed HPLC method, conducted as per ICH guidelines

\begin{tabular}{|c|c|c|c|c|c|c|c|}
\hline \multirow[t]{2}{*}{ Parameters } & \multirow[t]{2}{*}{ Level } & \multicolumn{2}{|c|}{ Mean of peak area $\pm \operatorname{SD}(n=3)$} & \multicolumn{2}{|c|}{ Mean of $t_{\mathrm{R}} \pm \mathrm{SD}(n=3)$} & \multicolumn{2}{|c|}{$\%$ RSD } \\
\hline & & Paracetamol & Caffeine & Paracetamol & Caffeine & Paracetamol & Caffeine \\
\hline Mobile phase & $+2(42: 58, \mathrm{v} / \mathrm{v})$ & $3495331 \pm 29038$ & $451035 \pm 7013$ & $2.61 \pm 0.004$ & $3.48 \pm 0.003$ & 0.040 & 0.035 \\
\hline \multirow[t]{2}{*}{ composition (methanol-water) } & $0(40: 60, \mathrm{v} / \mathrm{v})$ & $3520173 \pm 27354$ & $459450 \pm 6615$ & $2.63 \pm 0.001$ & $3.49 \pm 0.001$ & 0.022 & 0.017 \\
\hline & $-2(38: 62, \mathrm{v} / \mathrm{v})$ & $3583060 \pm 28741$ & $465567 \pm 6502$ & $2.64 \pm 0.002$ & $3.50 \pm 0.001$ & 0.039 & 0.026 \\
\hline \multirow[t]{3}{*}{ Flow rate $(\mathrm{mL} / \mathrm{min})$} & +0.1 & $3517790 \pm 30244$ & $456143 \pm 9235$ & $2.60 \pm 0.005$ & $3.47 \pm 0.001$ & 0.302 & 0.084 \\
\hline & 0 & $3520428 \pm 29842$ & $454031 \pm 9690$ & $2.63 \pm 0.002$ & $3.49 \pm 0.002$ & 0.066 & 0.060 \\
\hline & -0.1 & $3529487 \pm 22934$ & $460528 \pm 7093$ & $2.64 \pm 0.004$ & $3.51 \pm 0.003$ & 0.216 & 0.191 \\
\hline \multirow{2}{*}{ Column temperature $\left({ }^{\circ} \mathrm{C}\right)$} & 0 & $3505997 \pm 5123$ & $452544 \pm 3353$ & $2.63 \pm 0.001$ & $3.49 \pm 0.001$ & 0.022 & 0.029 \\
\hline & -2 & $3507754 \pm 7118$ & $451401 \pm 4052$ & $2.63 \pm 0.001$ & $3.49 \pm 0.002$ & 0.031 & 0.042 \\
\hline
\end{tabular}


conducted, there was a clear separation of the analytes peaks from that of degradation products. This indicated the good specificity of the proposed method.

Limit of Detection and Limit of Quantification. The LOD and LOQ of the analytes for the proposed method were determined based on the signal-to-noise ratio, and it was found to be $0.01 \mu \mathrm{g} / \mathrm{mL}$ for PCM and $0.02 \mu \mathrm{g} / \mathrm{mL}$ for CF, which indicated the method's suitability for the assay of PCM and CF over a wide concentration range.

Stress Degradation Studies. Stressed and unstressed sample solutions were prepared and analyzed as described earlier. The extent of degradations was calculated in terms of \% recoveries of the stressed and unstressed sample solutions, and the results for acidic and alkaline hydrolysis, oxidation, photolytic, and heat degradations are presented in Table 3.

PCM showed degradation of up to $15 \%$ after $24 \mathrm{~h}$ exposure to $2 \mathrm{M} \mathrm{HCl}$. However, $\mathrm{CF}$ remained stable in this acidic medium as no significant degradation was observed after $24 \mathrm{~h}$. However, on the contrary, both standard and test samples showed complete loss of $\mathrm{CF}$ upon exposure to $2 \mathrm{M} \mathrm{NaOH}$ for $24 \mathrm{~h}$, as no CF peak appeared in the chromatograms (Figure 4). This complete loss of CF peak may be associated with deprotonation triggered by $\mathrm{NaOH}$ which may make it less soluble in water and in the mobile phase of the proposed method since it contains a higher ratio of water (60\%). However, other peaks possibly from degradation products appeared, and about $18 \%$ of PCM content has decreased in the same standard and test samples after the $24 \mathrm{~h}$ exposure to $2 \mathrm{M} \mathrm{NaOH}$.
Another key finding of this study was the reversal of the oxidation effect exhibited by both the analytes upon exposure to $30 \% \mathrm{H}_{2} \mathrm{O}_{2}$. There was an initial decline in the percentage of the analytes content at $0 \mathrm{~h}$, but this was reversed at $24 \mathrm{~h}$. The photolytic degradation study did not reveal any significant changes in PCM and CF concentrations in both standard and test samples, and there was no additional peak that would have indicated the presence of degradation product in the chromatogram (Figure 5a). Similarly, the heat-induced stress did not result in any additional peak in the analytes' chromatogram (Figure 5b); however, a mild decrease in \% recovery was observed after $2 \mathrm{~h}$ of high-temperature exposure, which was more pronounced in PCM than in CF. In all cases of stress conditions, the retention times for PCM and CF remained unaltered. The analytes were quantified, and the degradation products were separated, which indicated the high specificity of the proposed method as well as its stability-indicating power.

Analysis of Pharmaceutical Formulation. The application of our HPLC method was demonstrated by recovering PCM and CF from a marketed tablet dosage form (Panadol ${ }^{\circledR}$ Extra) that was purchased from a local pharmacy in Penang, Malaysia. After extraction with the diluting solvent, appropriate dilution, and analysis, the test sample was found to contain $97 \%$ of PCM and 104\% of CF of the claimed concentrations of $500 \mathrm{mg}$ and $65 \mathrm{mg}$ for PCM and CF per each tablet, respectively. Their respective recovery's \% RSD was found to be 0.66 and 1.15 for PCM and $\mathrm{CF}$, respectively, which indicated that the method can be applied for routine analysis of PCM and $\mathrm{CF}$ in pharmaceutical dosage forms.

Table 3. Results for stress degradation studies of PCM and CF

\begin{tabular}{|c|c|c|c|c|c|}
\hline \multirow[t]{3}{*}{ Analyte } & \multirow[t]{3}{*}{ Degradation condition } & \multicolumn{2}{|c|}{ Standard } & \multicolumn{2}{|c|}{ Tablet dosage form } \\
\hline & & \multicolumn{2}{|c|}{ Recovery $(\%)( \pm \mathrm{SD}, n=3)$} & \multicolumn{2}{|c|}{ Recovery $(\%)( \pm \mathrm{SD}, n=3)$} \\
\hline & & At $0 \mathrm{~h}$ & At $24 \mathrm{~h}$ or $2 \mathrm{~h}$ for heat & At $0 \mathrm{~h}$ & At $24 \mathrm{~h}$ or $2 \mathrm{~h}$ for heat \\
\hline \multirow[t]{5}{*}{$\overline{\mathrm{PCM}}$} & No treatment & $98.10 \pm 0.03$ & $98.27 \pm 0.09$ & $95.69 \pm 0.02$ & $95.72 \pm 0.09$ \\
\hline & Acidic $(2 \mathrm{M} \mathrm{HCl})$ & $95.77 \pm 0.02$ & $82.69 \pm 0.19$ & $91.75 \pm 0.04$ & $82.83 \pm 0.01$ \\
\hline & Alkaline $(2 \mathrm{M} \mathrm{NaOH})$ & $92.99 \pm 0.01$ & $79.75 \pm 0.06$ & $92.49 \pm 0.01$ & $78.53 \pm 0.03$ \\
\hline & Oxidative $\left(30 \% \mathrm{H}_{2} \mathrm{O}_{2}\right)$ & $90.48 \pm 0.04$ & $99.90 \pm 0.21$ & $84.17 \pm 0.02$ & $94.37 \pm 0.02$ \\
\hline & Photolytic (at a wavelength of $365 \mathrm{~nm}$ ) & $98.21 \pm 0.02$ & $98.20 \pm 0.01$ & $95.51 \pm 0.04$ & $92.54 \pm 0.01$ \\
\hline \multirow[t]{6}{*}{$\mathrm{CF}$} & No treatment & $102.10 \pm 0.18$ & $102.22 \pm 0.21$ & $103.60 \pm 0.15$ & $103.74 \pm 0.12$ \\
\hline & Acidic (2 M HCl) & $101.37 \pm 0.07$ & $102.15 \pm 0.2$ & $92.23 \pm 1.07$ & $90.40 \pm 0.13$ \\
\hline & Alkaline $(2 \mathrm{M} \mathrm{NaOH})$ & $92.73 \pm 0.16$ & 0 & $92.52 \pm 0.15$ & 0 \\
\hline & Oxidative $\left(30 \% \mathrm{H}_{2} \mathrm{O}_{2}\right)$ & $89.26 \pm 0.09$ & $101.39 \pm 0.06$ & $81.39 \pm 0.05$ & $94.07 \pm 0.09$ \\
\hline & Photolytic (at a wavelength of $365 \mathrm{~nm}$ ) & $100.89 \pm 0.09$ & $100.07 \pm 0.05$ & $102.91 \pm 0.54$ & $96.88 \pm 0.08$ \\
\hline & Heat $\left(\right.$ at $\left.80^{\circ} \mathrm{C}\right)$ & $100.59 \pm 0.18$ & $99.80 \pm 0.08$ & $103.02 \pm 0.21$ & $94.88 \pm 0.12$ \\
\hline
\end{tabular}

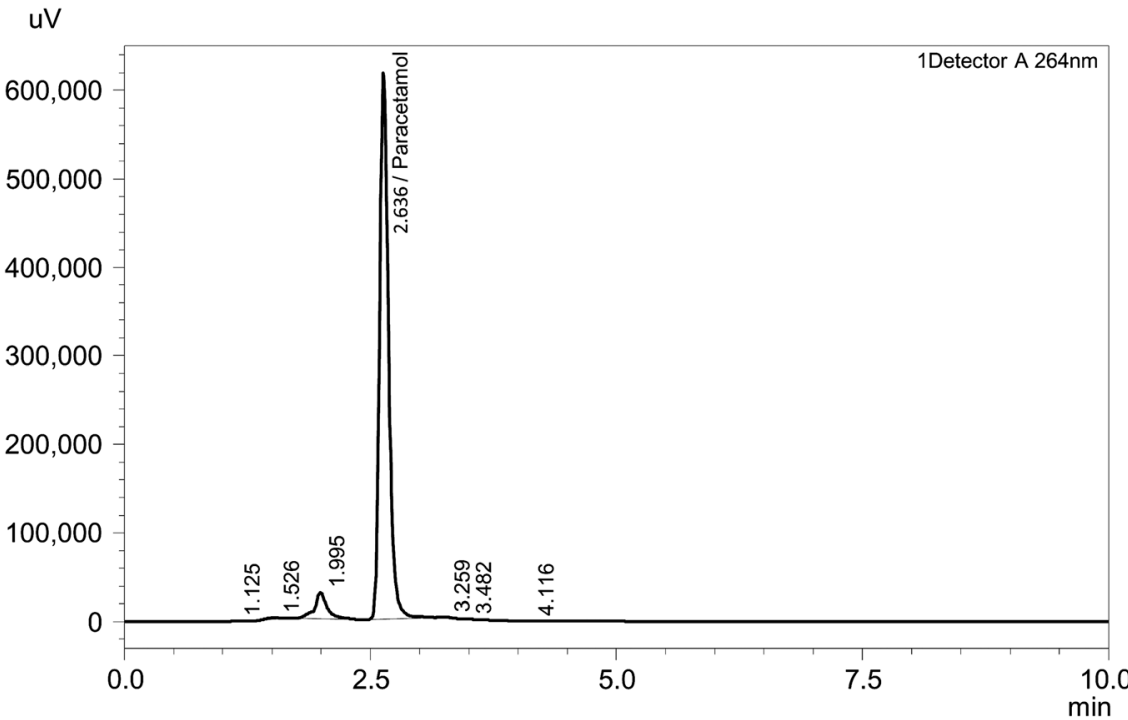

Figure 4. Chromatogram of PCM and CF after forced degradation by $2 \mathrm{M} \mathrm{NaOH}$ for $24 \mathrm{~h}$, indicating complete disappearance of caffeine peak 


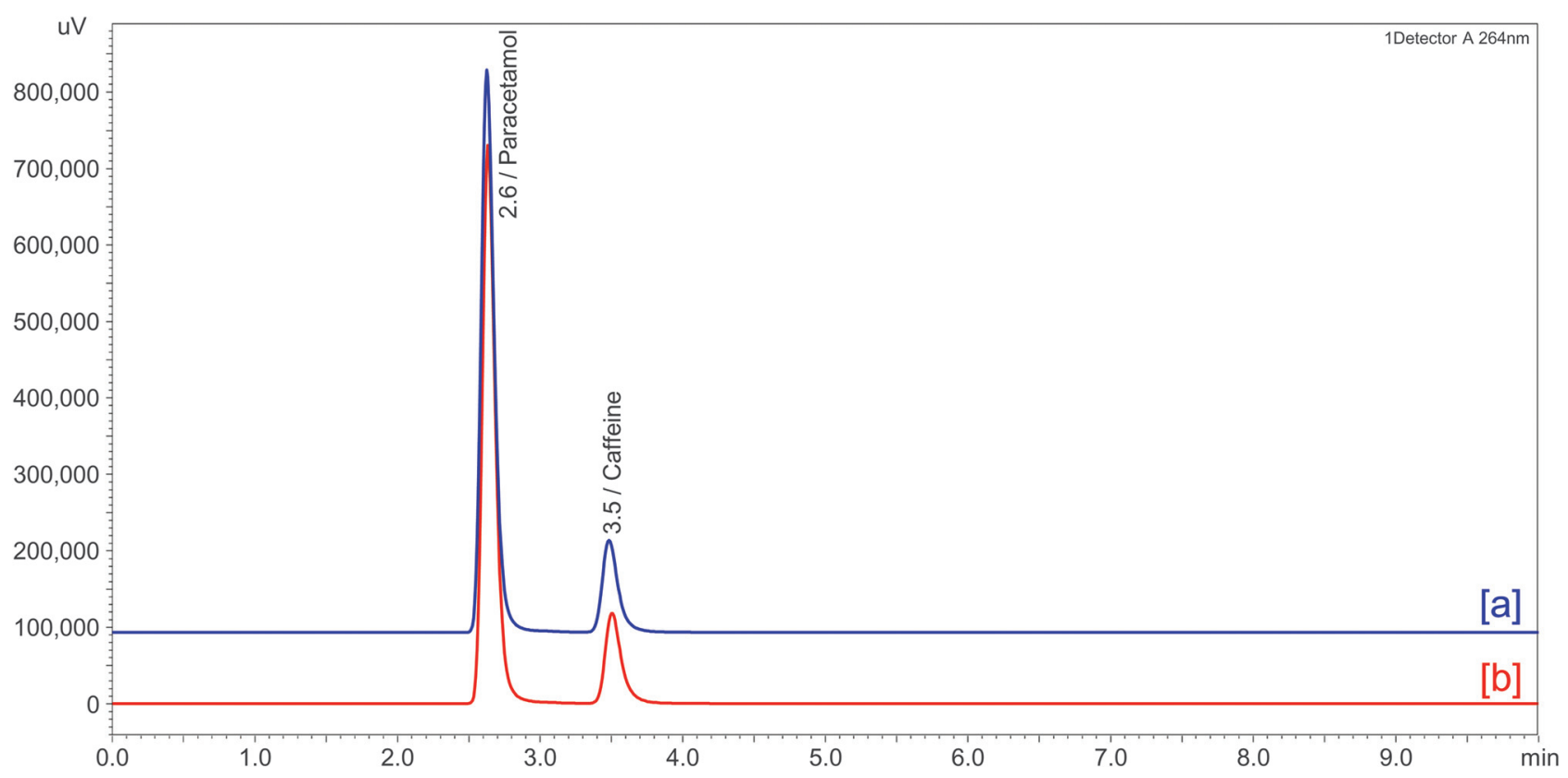

Figure 5. Chromatograms of PCM and CF for photolytic (a) and heat (b) of the stress degradation studies

\section{Conclusion}

An isocratic, economical, rapid, specific, and stability-indicating HPLC method was developed and validated for the simultaneous determination of PCM and CF. The method exhibited an upper hand compared with previously reported methods in terms of speed and simplicity. Additionally, the mobile phase (also used as extracting, column washing, and diluting solvent) was composed of only water and methanol (40\%), which rendered the method much cheaper than others. The present method also provided detailed account on quantification of PCM and CF under stress conditions, indicating the excellent specificity of the method and its stability-indicating power. The stress degradation studies revealed that $\mathrm{CF}$ is highly susceptible to alkaline hydrolysis, while both PCM and CF undergo moderate reversible degradation when subjected to oxidative stress. The method was validated according to ICH guidelines, and the validation results confirmed that it is specific, linear, accurate, precise, and robust. Therefore, the present method was found to be suitable for routine analysis of PCM and $\mathrm{CF}$ in pharmaceutical dosage forms and in quality control.

\section{Conflict of interest}

The authors declare no conflict of interest.

Acknowledgment. The authors would like to thank Usmanu Danfodiyo University Sokoto, Nigeria for funding this work and Universiti Sains Malaysia (USM) for providing some facilities to conduct the work. Mr. Nafiu Aminu and Mr. Nasir Hayat Khan gratefully acknowledge the USM fellowship support provided by USM.

\section{References}

1. nature.com. Combination Drug Therapy, http://www.nature.com/subjects/ combination-drug-therapy (accessed May 9, 2017).

2. Wu, M.; Sirota, M.; Butte, A. J.; Chen, B. Pacific Symp. Biocomput. $\mathbf{2 0 1 5}, 20,68-79$

3. oncosec. What is Combination Therapy? http://oncosec.com/what-iscombination-therapy/ (accessed May 11, 2017).
4. Gilmore, B.; Michael, M. Am. Fam. Physician 2011, 83, 271-280.

5. Ferrari, M. D.; Roon, K. I.; Lipton, R. B.; Goadsby, P. J. Lancet 2001 $358,1668-1675$

6. Ali, Z.; Burnett, I.; Eccles, R.; North, M.; Jawad, M.; Jawad, S.; Clarke, G.; Milsom, I. Curr. Med. Res. Opin. 2007, 23, 841-851.

7. Sweetman, S. C. Martindale: The Complete Drug Reference, Thirty-six Pharmaceutical Press: London, 2009, 2009.

8. Jozwiak-Bebenista, M.; Nowak, J. Z. Acta Pol. Pharm. 2014, 71, 11-23.

9. Chandrasekharan, N. V.; Dai, H.; Roos, K. L. T.; Evanson, N. K.; Tomsik, J.; Elton, T. S.; Simmons, D. L. Proc. Natl. Acad. Sci. U. S. A. 2002, 99, 13926-13931.

10. Frizzarin, R. M.; Maya, F.; Estela, J. M.; Cerdà, V. Food Chem. 2016 212, 759-767.

11. Nehlig, A.; Daval, J.-L.; Debry, G. Brain Res. Rev. 1992, 17, 139-170.

12. Ahmad Bhawani, S.; Fong, S. S.; Mohamad Ibrahim, M. N. Int. J. Anal. Chem. 2015, 2015, 1-7.

13. Straube, A.; Aicher, B.; Fiebich, B. L.; Haag, G. BMC Neurol. 2011, 11,43 .

14. Migliardi, J. R.; Armellino, J. J.; Friedman, M.; Gillings, D. B.; Beaver,

W. T. Clin. Pharmacol. Ther. 1994, 56, 576-586.

15. Goldstein, J. Inflammopharmacology 2001, 9, 51-61.

16. Aktaș, A. H.; Kitiş, F. Croat. Chem. Acta 2014, 87, 69-74.

17. Wang, A.; Sun, J.; Feng, H.; Gao, S.; He, Z. Chromatographia 2008 67, 281-285.

18. Acheampong, A.; Gyasi, W. O.; Darko, G.; Apau, J.; Addai-Arhin, S. Springerplus 2016, 5,625 .

19. Cunha, R. R.; Chaves, S. C.; Ribeiro, M. M. A. C.; Torres, L. M. F. C.; Muñoz, R. A. A.; Dos Santos, W. T. P.; Richter, E. M. J. Sep. Sci. 2015, 38 , $1657-1662$.

20. Tefera, M.; Geto, A.; Tessema, M.; Admassie, S. Food Chem. 2016, $210,156-162$

21. Tavallali, H.; Zareiyan, S. F.; Naghian, M. J. AOAC Int. 2011, 94, 1094-1099.

22. Hiremath, S. N.; Bhirud, C. H. J. Taibah Univ. Med. Sci. 2015, 10, 271-277.

23. Khalid, K. M.; Kayesh, R.; Islam, H.; Rahman, A. Am. J. PharmTech Res. 2015, 5, 348-360.

24. Pal, N.; Rao, A. S.; Kumar, P. R. Int. J. Pharma Sci. 2015, 5, 1100-1107.

25. ICH. Stability Testing of New Drug Substances and Products, Q1A (R2) https://www.ich.org/fileadmin/Public Web Site/ICH Products/Guidelines/ Quality/Q1A_R2/Step4/Q1A_R2_Guideline.pdf (accessed Mar 13, 2017).

26. ICH. Validation of Analytical Procedures: Text and Methodology, Q2 (R1) http://www.ich.org/fileadmin/Public Web Site/ICH Products/Guidelines/ Quality/Q2 R1/Step4/Q2 R1 Guideline.pdf (accessed Sep 5, 2016).

27. Shabir, G. A. J. Chromatogr. A 2003, 987, 57-66.

28. Nagasarapu, M.; Dananna, G. J. Young Pharm. 2015, 7, 81-88.

29. Aminu, N.; Chan, S.-Y.; Khan, N. H.; Toh, S.-M. Acta Chromatogr. 2017, 1-6.

30. FDA. Validation of Chromatographic Methods http://www.fda.gov/ downloads/drugs/guidances/ucm134409.pdf (accessed Sep 21, 2016). 